Session 3142

\title{
Student Participation in Field Research Project Choice and Evaluation
}

\author{
Charles W. N. Thompson
}

Northwestern University

\begin{abstract}
Complementing courses which teach theory and practice of management of engineering organizations are courses which provide the student with an opportunity to examine or test these teachings through designing and carrying out (at least) pilot tests in real organizations. Choice of projects and evaluation of the students' design efforts by the instructor assures that both the subject matter and the methods to be employed maximize the objectives of the course.
\end{abstract}

Student choice and student evaluation, while increasing the interest and motivation of the student, present potentially greater risks in attaining course objectives. For individual projects, there is the added problem of an unpredictably wide variety of choices. This paper reports the results of progressively encouraging student participation in both of these areas.

The paper is based upon over thirty years of teaching undergraduate and graduate field research courses.

Introduction

The focus of this paper is one of many teaching techniques, the use of field projects, and a particular type of project, applying the methodology of field research to testing an a priori hypothesis concerning the management of technology. This is a long established practice, particularly in the training of doctoral students who will be studying the management of real engineering organizations, although it is underreported in the current periodical literature. The usefulness of this technique to practicing engineers and engineering managers, as distinguished from researchers, will be discussed as a basis for justifying its application to undergraduate engineering students who may have no present interest in a career in research. Particular attention will be given to two evolving areas: student choice of projects; student critiquing of projects.

No justification is required for the choice of projects by the instructor; from experience, the instructor can assure that the projects are suitable for the application of the syllabus theory and methodology teachings, and this facilitates both economies in preparation and building on prior 
exposure. While various degrees of freedom to select from some subset are not uncommon, providing great latitude in subject matter and in choice of the specific variables of interest raises potential problems and a challenge to find ways to allow latitude without chaos ${ }^{7}$.

Similarly, the instructor's responsibility for evaluating and grading, and in providing feedback and guidance during the course is clear. The instructor brings experience and training in both theory and method, at least to a larger degree than the student, which provide critical guidance in a successful learning experience for the student. It may be problematic whether other students can quickly contribute to this process to the benefit of the student being critiqued, and to their own benefit.

It has been suggested that we need a transformation from teacher-centered to student-centered engineering education ${ }^{2}$. And the focus on an objective-based undergraduate research project experience (for purposes paralleling but different from that discussed here) has been reported ${ }^{3}$. Simon, in a brief comment on the learning process, notes the value of ill-structured problem solving in the design process, although he did not have in mind field research design. He also recounts his chess playing research and points out that recognizing patterns, something critical to the critiquing process to be discussed, is a large part of the skill in numerous fields of expertise ${ }^{4}$.

\section{Brief Description of the Class}

The course in field research methods which is the focus of this paper originated as the second part of a two-part course in organization theory for doctoral students, and this function has continued to the present. Thirty years ago an opportunity to implement the effort of Donald Campbell to encourage administrative experimentation in real organizations ${ }^{1}$ occurred when the author was invited to teach a revised version of the course at another university. The results were reported in a prize winning paper ${ }^{5}$. These graduate students were almost all engineers and engineering managers working full time, and, for them, the course was not to prepare them to be academic researchers but to help them as managers by providing a basis for evaluating their own management changes and to evaluate input from others, e.g., consultants and the literature. Although the course was an elective in a graduate engineering management program, it attracted many students. This background is provided to explain the origin of the changes in the undergraduate course which will be discussed below. The paralleling undergraduate course originally covering theory was initially supplemented by an organizational design course, which had a limited life, and then by a field research methods course, paralleling the graduate course. Drawing upon the successful application at the graduate level, the field research methods course continued to evolve into the present course which will now be described.

After an introductory week, the course consists of lectures on methodological topics and student presentations. The presentations start in the third week and take up half the class time for the rest of the quarter. During the course, the students are required to do two kinds of written assignments. First, they must find an article in the research literature on a specified topic, and prepare an abstract which also describes the author's basis for the article and the student's evaluation of the article. Second, they must identify an organizational problem and describe it in hypothesis testing terms, design a field research study or experiment which could test the hypothesis, and then create and pilot test a variety of instruments and protocols. The final assignment is to tie all of this together, including an evaluation of what remains to be done, in a 
formal final report. Each student is also required to make at least one oral presentation of the research design.

The course is offered two or three times a year with class sizes ranging from about 15 to 50 , and the students are primarily juniors with a few seniors. Course loads currently limit the class to departmental majors, and many of them use the skills they develop in this course in senior capstone project courses and some in independent study involving honors projects or other research under the guidance of a faculty member. Over the years the course has slowly evolved with two major changes: first, providing more help and guidance in choosing a project without substituting the instructor's preferences in subject matter; second, substituting a primarily peer critique of the designs for that of the instructor. These will be discussed below.

\section{Selecting Projects}

To varying degrees participation in or even taking leadership in selecting projects by doctoral students or part time students with full time jobs who are working in a graduate program may grow out of or be justified by their relevant experience, and, in some cases, advanced academic preparation. Much less likely is relevant experience or preparation to be found in undergraduates, and this is certainly true of those in engineering. What engineering students do bring, however, is the beginnings of the engineering preference for trying out solutions, i.e., building a breadboard model and plugging it in to see if they can get "smoke and noise."

Early attempts to encourage choice were often greeted with hostility or even terror. It was clear that freedom needed some help, and a number of methods were developed, with the imperative to do so without taking back too much of their freedom to choose.

The first method was to try to identify characteristics of projects which would increase the likelihood of success in the class without directly or indirectly forcing the student to choose a project which the instructor wanted or would have chosen. Originally, these were listed as a short handout but, when this process was recognized as similar to a process used for evaluating technical systems proposals within the Air Force and the Department of Commerce ${ }^{6}$, the list was converted and expanded into a parametric factor evaluation (PFE) form which has now been used for a number of years. A copy illustrating this is provided in Table 1 PFE Factors for Course Related Research Projects. A quick inspection will show that these are commonsense characteristics but still allow a wide latitude in choice of projects.

Experience showed that there were some additional characteristics which affected the usefulness of a project for course purposes. Although the course title and syllabus provided some guidance, some students still would choose projects which were interesting and potentially good research candidates but which weren't helpful in this course. The first, and most obvious, additional characteristic was that the project should require gathering data in the real world, i.e., use methods such as interviewing, questionnaires, observation, records. Projects which required none of these, e.g., abstract problems, or required only one, e.g., a physics lab experiment, would limit the ability to carry out the weekly assignments. A second, and more subtle, characteristic was a priori hypothesis testing. Clearly, descriptive and exploratory research are important and relevant; however, contrary to expectations, these require substantially more work in order to achieve any comparable credibility, and, for beginning "researchers," the simplicity and 
directness, in comparison, of hypothesis testing greatly facilitates both critiquing and understanding. The power of a priori hypothesis testing was made clear by the illustration provided by "The Connecticut Yankee in King Arthur's Court." The third characteristic is technology management, or the choice of projects which directly or indirectly affect the ability to organize and direct technical organizations or projects. This is, probably, not as critical an issue, and this requirement is not used in any of the systems courses, both graduate and undergraduate, taught by the instructor.

The students are provided with a number of handouts which they may use to help them in choosing a project and in working on it, and most of these are available for reference ${ }^{8}$.

As a first assignment before selecting their projects, the students are given two topics and asked to choose an hypothesis concerning each, and then describe it in three forms: propositional statement, graphical or plot of expected data, and a statement outlining why changes in the independent variable are accompanied by (and/or cause) changes in the dependent variable. To help them get a feel for the process, the instructor goes through several examples. In addition, a simple Cartesian coordinate example is used to refresh their recognition of the simplest type of relationship between two variables, and what the terms independent and dependent variable and hypothesis mean. The instructor goes through several examples to help them get a feel for the process. All of this is intended to help them focus on the identifying and defining process in preparation for the next step.

In their second assignment, the students are asked to briefly describe a project of their own choice in sufficient detail so the instructor will understand what the project expects to prove, and then to evaluate it against the PFE factors discussed previously (Table 1). They are also provided with an extensive list of prior student projects, and a compilation similar to the handout is provided in Table 2 Selected Projects and Suitability Scale. In addition, the rating system used to provide feedback to the students has been included.

The instructor's review will neither approve nor disapprove of the project; the grade will be solely based on whether they have reasonably provided information about the proposed project and use of criteria. In response to student requests for feedback (and to alert them to potential problems the instructor is aware of), an evaluation of how suitable the project is for class purposes is also provided. This evaluation is explicitly stated to not affect the grade, and is primarily to allow the students to decide whether to continue or to change the project to avoid untoward difficulties. The main reasons for considering a change include the following:

Is exploratory or descriptive research which would require a much larger effort to achieve reasonable learning

Is attempting to prove the null hypothesis, with similar effect

Hypothesis not clear or multiple hypotheses

Involves limited field research methods, e.g., a purely physical test.

Experience has indicated that most identify reasonably appropriate hypotheses the first time, that some need to consider choosing another problem, and a very few, usually no more than one or two in a class, run into serious choice problems which require extended discussion with the instructor. 


\section{Critiquing Projects}

The instructor reviews and grades the weekly written assignments on each project and provides comments and suggestions, usually in the form of pointing out omissions. Similarly, the written final report is reviewed against a template, and this contributes a significant part of the grade.

In the early years, students were required to make oral presentations on their designs, and the instructor would ask questions, particularly to uncover areas which had not been covered, and would also take advantage of important design deficiencies to give mini lectures, considered a more effective way than just seriatim lecturing. At some unremembered and unremarked point, the instructor, who always sat at the back of the class, asked the class to start the critiquing and was almost immediately surprised with the perceptiveness of the questions. Over time this evolved into providing a framework which prompted them to ask, in order, questions to make sure they understood the hypothesis, and then the method of testing it, and then to explore questions that interfered with their ability to have confidence in the expected results. These questions were formalized in a document which listed representative questions and assigned specific questions to each student on a rotating basis. The questions are set out in Table 3 Research Project Presentation Checklist.

It was made clear to the students that they were required to make a presentation, but they would not be graded on it, whether excellent or poor. They would, however, be graded upon their questions as part of the listening audience. This encourages attendance at the presentation sessions, and only a very few students do not actively participate.

The success of this has been measured only anecdotally. Teaching assistants who join the instructor, including senior doctoral students, express shock and amazement at the quality and quantity of questions, suggesting that these undergraduates are receiving a collegial input usually shared only among advanced doctoral students. During each presentation, the instructor writes down his questions, separately noting those few he believes would not be discovered by less experienced listeners. Most of the time, all of his questions are anticipated, including many of the unusual ones. Why this works so well is not clear. Perhaps it is the fact that the students largely share a common experience which provides most of the hypotheses, and they "know the territory," something many researchers consider necessary to good design. Some selective taping of these presentations has begun to provide a record of the process.

\section{Summary}

This experience suggests that a considerable amount of the critical processes of choosing the problem and critiquing the proposed project can be transferred to the students and that advantages to the student are achieved without sacrificing course objectives. Sufficient guidance can be provided without significantly limiting student choice. Student critiques have been surprisingly effective; recording of class notes has provided a valued input to the presenter in preparing the required final report, and student recognition of design issues is constantly reinforced not only by their own questions but also by those of their classmates. Shared experiences provide not only a basis for critiquing but also increase the interest of the students in one another's projects. However, as is true with most project courses, the burden on the teacher 
is significant and, in this case, increased by the necessity of responding to a wide variety of research initiatives.

Bibliographic Information

1. Campbell, D. T., "Administrative Experimentation, Institutional Records, and Nonreactive Measures," in Improving Experimental Design and Statistical Analysis, J. C. Stanley and S. M. Elam, Eds., Chicago, Rand McNally, 1967, pp. 257-291.

2. Catalano, G. D. , and Karen Catalano, "Transformation: From Teacher-Centered to Student-Centered Engineering Education," Journal of Engineering Education, Vol. 88, No. 1, January 1999, pp.59-64.

3. Narayanan, R. M., "Use of Objective-Based Undergraduate Research Project Experience as a Graduate Student Recruitment Tool," Journal of Engineering Education, Vol. 88, No. 3, July 1999, pp. 361-365.

4. Simon, H. A., "What We Know About Learning," Journal of Engineering Education, Vol. 87, No. 4, October 1998, pp. 343-348.

5. Thompson, C. W. N., "Administrative Experiments: The Experience of Fifty-Eight Engineers and Engineering Managers, IEEE Transactions on Engineering Management, Vol. EM-21, No. 2, May 1974, pp 42-50.

6. Thompson, C. W. N. "Another View of the Forest--Parametric Factor Evaluation," Proceedings of the 1989 IEEE International Conference on Systems, Man, and Cybernetics, Boston, MA, November 14-17, 1989, pp.

7. Thompson, C. W. N., "Student Choice of Field Projects," Proceedings, ASEM National Conference, Tampa, FL, October 2-5, 2002, pp. 211-215.

8. Thompson, C. W. N. (Various course materials available online at www.iems.northwestern.edu.)

Biographical Information

Charles W. N. Thompson is a professor of industrial engineering and management sciences. His teaching and research focuses on field research methodology, systems engineering and analysis, information systems, and project management. He has an M.B.A. and LL.B, in addition to his doctorate in industrial engineering. He previously spent twelve years in engineering management with the USAF and industry. 
Table 1 PFE Factors for Course Related Research Projects

I. BIG ENOUGH (Non-trivial)

5. Challenging, need hard/smart work

4. Probably enough work to do

3. Not clear

2. Not really much to do

1. Solution is known, anybody can solve
III. COURSE-RELATED CONTENT

5. Clearly requires application of course related "sciences" (behavioral, technical, etc.)

4. Sufficient application or focus to meet course requirements

3. Not clear

2. May be difficult to relate to course

1. Content/focus unrelated to course V. REAL (Not abstract or hypothetical)

5. Specific problem located at a specific time and place in the real world

4. Probably can pin down site and time

3. Not clear if can pin down the problem

2. Expect a lot of difficulty in pinning

1. Abstract, philosophical, or normative VII. EMPIRICAL (Field research)

5. Requires new data obtained directly (or nearly so) from specific real world phenomena of interest

4. Major focus on field data

3. Lab experiments

2. Literature search or simulation

1. Primarily abstract models

\section{HYPOTHESIS TESTING}

5. New data will confirm (or refute) the proposed hypothesis

4. New data expected to confirm

3. Hope for above, but expect lots of difficulty with parameters, design changes

2. Start with prior theory, but is really exploratory and/or descriptive only

1. Is exploratory and/or systems design
II. SMALL ENOUGH (Solvable)

5. Manageable, within my resources (time, dollars, manpower)

4. Probably can scale it down if need to

3. May be possible to scale down

2. Large number of variables, lots of problems

1. Dilemma or matter of opinion (e.g., subjective, matter of taste, political)

IV. STABLE (Neither new nor over)

5. Lots of background available; and won't be solved before we finish

4. Old but changing problem; partial solutions may be available before we finish

3. Not clear whether is stable or not

2. Likely to change a lot while I work on it

1. Either a brand new problem or will be over (solved) before I can solve it

VI. ACCESS TO INFORMATION

5. Openly available, both people (and records), will be great asset to project

4. Probably available

3. Not clear whether access difficult

2. Potential difficulties in access

1. Sources likely to be unavailable VIII. CUSTOMER (Research)

5. Challenging problem to peer group (i.e., scientists, journal editors)

4. Same, except with reference to a less critical subset ("applied research")

3. May not be "novel" or publishable but demonstrates research competence

2. Serves my curiosity needs only

1. Might impress my own mother

USING THE RATINGS

The project will help rather than hinder the work during the quarter if Factors I, II, VIII, and IX are at least a 3 and the other factors are at least a 4. 
Table 2 Selected Projects and Suitability Scale

\section{Project Hypotheses}

Number of roommates --> Number of study hours in room

Alcohol consumption -- $>$ Number of sexual partners

Student organization officers --> Lower GPA

Fraternity membership --> Lower grades

Living off/on campus --> Class attendance

Attended private high school --> Higher GPA

Parents' education level --> Student's GPA

Gender --> Effect of competition on performance

Same major as roommate --> GPA

Regular exercise --> GPA

Greek membership --> Cheating in school

Study abroad --> Satisfaction with college

Group study --> Grades

More student financial contribution to education --> Higher GPA

Play musical instrument --> Performance in math classes

Exposure to music prior to or during --> Better athletic performance

Classes outside of major --> Better grades than major classes

More extracurricular activities --> Get more sleep

Sittting in the back row --> Lower GPA

Single room --> Higher grades

Students with part time jobs --> Lower GPA

Not on meal plan first year --> Better grades

Dorm greater distance from clinic --> Likelihood to go for treatment

Frequency \& quantity of alcohol use --> GPA

Single vs double major --> GPA

Engineering students -- $>$ Less active in community service

Transfer students -- $>$ happier

MEOP --> earlier participation \& leadership in student organizations

NROTC --> more involved in campus activities

Students a relationship --> Higher GPA

Intramural sports --> More campus leadership positions

Students who use meal plan --> Obtain better nutrition

Non-revenue varsity athletes --> Higher GPA's

Varsity sport's most active quarter --> Higher GPA's for athletes

Engineering students --> Less informed on current events

Living on campus -- $>$ healthier eating \& exercise habits

Exercise regularly -- $>$ better grades

Eating breakfast regularly --> Higher GPA

\section{Suitability}

Instructor's

estimate of how

suitable the project

will be in meeting

course requirements:

4 Great "fit" with course requirements; good work should pay off well

3 Should be fine; reasonable effort and smartness should pay off

2 Need to be careful; some attention to selected areas

1 Potential problem(s), but extra work should overcome it (them)

0 Serious problems; need something more than a strong effort 
Table 3 Research Project Presentation Checklist

\begin{tabular}{|c|}
\hline What he set out to do (Research Objective) \\
\hline $\begin{array}{l}\text { 1. Is the hypothesized relationship he proposes to test (or has tested) clearly stated and } \\
\text { identified as such? }\end{array}$ \\
\hline $\begin{array}{l}\text { 2. Is the Xiv clearly described in terms of "what" varies, over what range, in what form (ratio, } \\
\text { interval, etc.), i.e., do we know the values it takes on? }\end{array}$ \\
\hline 3. Is the Xdv clearly described? \\
\hline 4. Is the form of the relationship clear (linear, complex, $2 \times 2$, range limited, etc.)? \\
\hline $\begin{array}{l}\text { 5. Is the "theory" of "what is going on" clearly stated, is it related to the prior art and/or to } \\
\text { practice in the real world? }\end{array}$ \\
\hline $\begin{array}{l}\text { 6. Are potential (or actual) alternative explanations for the (expected) results based on the } \\
\text { "theory" above, clearly identified? }\end{array}$ \\
\hline $\begin{array}{l}\text { 7. Is what we will know as a result of this project that we didn't know before clearly spelled } \\
\text { out, and with reference to the prior state-of-the-art? }\end{array}$ \\
\hline How he will test it (and/or did test it) \\
\hline $\begin{array}{l}\text { 8. Is the choice of site and subjects and sample clear? Was it a forced or limited choice? } \\
\text { What was the process and why? If not ideal, what Xpar are introduced? }\end{array}$ \\
\hline $\begin{array}{l}\text { 9. Is the design clear, e.g., a time series (longitudinal) or control group (cross sectional) or } \\
\text { what? If not ideal, what Xpar are introduced? }\end{array}$ \\
\hline $\begin{array}{l}\text { 10. Will (does, did) Xiv vary as required by the hypothesis and research design? If an } \\
\text { experiment, can he manipulate it? }\end{array}$ \\
\hline 11. Are (were) measures of Xdv related to corresponding measures of Xiv? \\
\hline $\begin{array}{l}\text { 12. Are (were) Xiv and Xdv easily and confidently measured? Are (were) the definitions and } \\
\text { indicators clear (to you, to interviewers, etc.)? Are multi-measures available? }\end{array}$ \\
\hline 13. Are (were) measures of Xpar available? \\
\hline $\begin{array}{l}\text { 14. Is (was) the method of analysis clear? How about methods of aggregation? methods of } \\
\text { establishing confidence in the results? Were the methods appropriate to the kind of data } \\
\text { and the requirements of the hypothesis? }\end{array}$ \\
\hline What did you think of it \\
\hline $\begin{array}{l}\text { 15. What other explanations are there for his results (i.e., Xpar) which he didn't disclose? Or } \\
\text { even think about? }\end{array}$ \\
\hline $\begin{array}{l}\text { 16. Is the process one which provides checks or tests of its credibility? How dependent are we } \\
\text { on his competence and his integrity and his bias? Is it replicable? Is there an audit trail? } \\
\text { Are his methods ones which have been tested or proven by others? }\end{array}$ \\
\hline
\end{tabular}

\begin{tabular}{|l|}
\hline Additional Checklist Items \\
\hline 17. Which Campbell \& Stanley design was used? or which is closest? \\
\hline 18. Which Thompson Extension design was used? or which is closest? \\
\hline 19. Does it meet PFE factors \# 1\&2, i.e., is the project too big or too small? \\
\hline 20. Does it meet PFE factor \# 3, i.e., is it course related (people in organizations)? \\
\hline 21. Does it meet PFE factors \#4\&5, i.e., is it "stable" and "real"? \\
\hline
\end{tabular}

